Volume 5, Issue 2, June 2020, pp. $160-174$

DOI: $10.23917 /$ jramathedu.v5i2.10556

p-ISSN: 2503-3697, e-ISSN: 2541-2590

\title{
Pre-service teacher's mathematical knowledge for teaching in problem-based learning
}

\author{
Ifada Novikasari \\ Tadris Matematika, Institut Agama Islam NegeriPurwokerto, Indonesia \\ Corresponding author: ifa_da@iainpurwokerto.ac.id
}

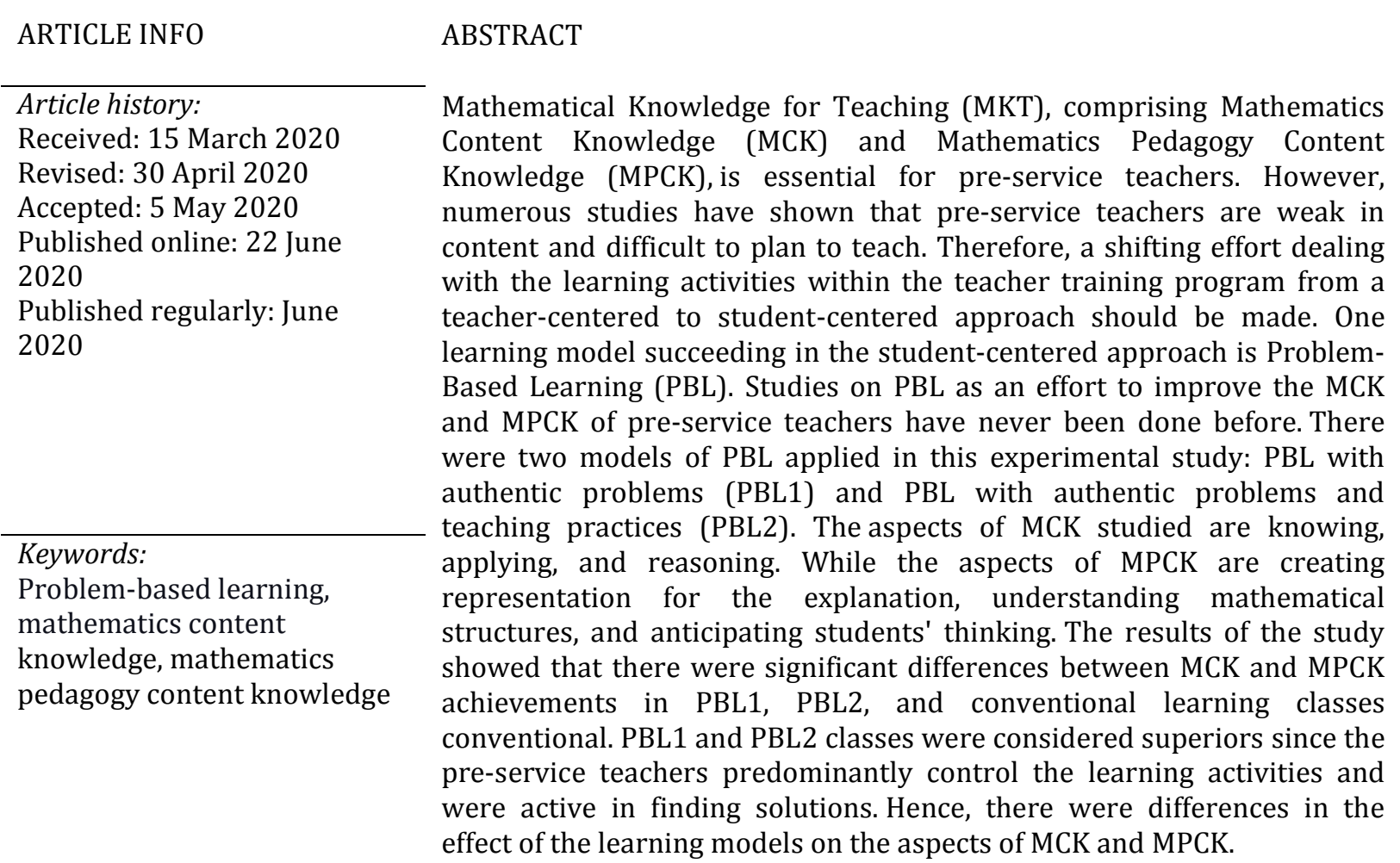

(C)2020 Universitas Muhammadiyah Surakarta

\section{Introduction}

The challenge of Indonesian education in creating reliable and accountable next generation is not borne by the government only as of the policymaker but also those executing the programs in the field namely teachers. The government's policy to reform the national curriculum into the "2013 Curriculum" was once a controversy. There were many education practitioners, especially teachers, who were not good enough in applying scientific approaches (Gunawan, 2017). The dramatic reform, according to Corcoran (1995), generated hopes for students, but consequently, it required the teachers to master new skills, bare more responsibilities, and make new changes in their teaching practices.

The objectives of teacher training programs are to provide pre-service teachers with proper qualifications as teachers. Experiences in the teacher training program will influence and strengthen the identity of an individual as a future teacher (Grevholm,

To cite this article:

Novikasari, I. (2020). Pre-service teacher's mathematical knowledge for teaching in problem-based learning. JRAMathEdu (Journal of Research and Advances in Mathematics Education), 5(2), 160-174. doi:https://doi.org/10.23917/jramathedu.v5i2.10556 
Millman, \& Clarke, 2009). Therefore, the curriculum of a training institution should include a lot of practices to build a profound experience for pre-service teachers. Generally, the teacher-training curriculum covers contents, pedagogic knowledge, and teaching practices. The content mastery, when regarded to competency, may be defined as the teacher's professional competence, pedagogic knowledge, and teaching practices.

Some current research developments studying the content knowledge (CK) and pedagogic content knowledge (PCK) have been mostly focused on Mathematics subjects. This specialization is prepared for the complexity of the subject that needs to be mastered

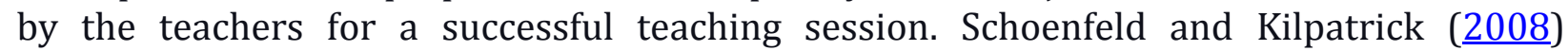
explained that mathematical teaching highly required a special knowledge that the teachers should not only well master and teach the contents, but also be knowledgeable on others, such as the concept representation's learning effectiveness, unusual strategies to solve the mathematical problems and understand the students' mathematical thinking ways. The research conducted by Deborah, Ball, Hill, and Bass (2005) and Tatto et al. (2008) revealed that the Mathematical Knowledge for Teaching (MKT) covering the Mathematics Content Knowledge (MCK) and Mathematics Pedagogy Content Knowledge (MPCK), is greatly necessary for teacher's success in teaching mathematics at school.

Teachers' MCK without pedagogical knowledge mastery will affect a failure in achieving the learning objectives. Some teachers tend to teach only to perform the curriculum, finish the textbooks, or carry out the lesson plans, even though they know that the students will eventually forget most of what they have learned if the teachings are not based on their needs (Bacon \& Stewart, 2006). The development of MKT in the forms of content mastery, content teaching methods, and understanding mathematical ways of

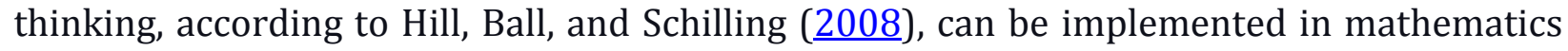
the teacher education program and teacher professional development. The MKT development could be a valuable addition to the program's curriculum because the students of this program are adults with high self-confidence (Ortiz-Ordoñez, Stoller, \& Remmele, 2015). The program's learning process gives the learners spaces for self-proof and reflection (Kennedy, 1999). The program also enables learners to re-examine their knowledge and balance their experiences (Sorge, Kröger, Petersen, \& Neumann, 2019).

The teaching methods in teacher education programs, by Darling-Hammond (1997), may be implemented through the activities of analyzing case studies, studying researches on mathematic classes, developing assessment competence, and evaluating a portfolio. Through these activities, the pre-service teachers could find out an appropriate method to be applied to their real practical problems. The method of case study analysis, by Duch, Groh, and Allen (2001) and Levin (2001), brings the teaching relevant to the learners' needs, one teaching model regarded as a case study is Problem Based Learning (PBL). In $\mathrm{PBL}$, problems are given at the beginning of the learning process as a stimulus for implementing skills to solve problems or provide reasoning. The stimulus was given that the students can find knowledge or information in understanding the problem-solving mechanisms. Evaluating research results, journal articles, or learning practices can also be applied in PBL model (Darling-hammond \& National Commission on Teaching \& America's Future (U.S.), 1997; Levin, 2001). Extensively, according to Skott (2019) educators need to relate learners' initial knowledge to the learning contents. These techniques could help learners to achieve their success.

There are two PBL models used in this study. The first model, denoted by PBL1, is pure PBL whose teaching materials include authentic mathematical problems. Whereas, the second model, denoted by PBL2, is modified PBL whose teaching materials comprise authentic mathematical problems as well as the analysis of groups' professional 
performances (works) on mathematics materials that are difficult to teach at the elementary level (Savin-Baden, 2003).

This study mainly focuses on teaching mathematics knowledge factors: MCK and MPCK, PBL1, PBL2, and conventional learning. No previous experimental researches have been conducted by comparing the two types of PBL and conventional learning. Therefore, in the recent study, the effect of PBL1, PBL2, and conventional learning on the aspects of MCK and MPCK will be investigated. The research questions of this study are: whether or not there are any differences in the MCK progress of the pre-service teachers who experience learning with PBL1 and PBL2. Whether or not there are any differences in the MPCK progress of the pre-service teachers who experience learning with PBL1, PBL2, and conventional learning. This study will contribute to the teaching practices in teacher education programs.

\section{Research Methods}

This quasi-experiment study is conducted with a non-probability group that a specific group was used as the research sample (Cohen, Manion, \& Morrison, 2007). The quasiexperiment was selected because the participants cannot be limited from getting outside influences. The population of this study was all pre-service teachers of the $4^{\text {th }}$ semester of 2016-2017 academic year in a state university in Central Java, the study program of Elementary Teacher Education. The total population was 264 pre-service teachers. As a non-probability group design, the experimental and control groups may have different characteristics so that it can influence the independent variables. Therefore, the decision for the experimental and control groups was made as carefully as possible to reduce the effect of other variables on the independent variables. Two selected experimental classes were PBL model 1 (22respondents) and PBL model 2 (30respondents) while the control class (17respondents) was taught using the conventional learning model.

The instruments used were MCK and MPCK tests. A test of Students' Beginning Content Knowledge Level (BCKL) was given to reveal the beginning knowledge level of the pre-service teachers on the prerequisite materials of previous lecture content mastery. The MCK and MPCK tests were adopted from Ma (1999) and Cheang, Yeo, Chan, and Lim-Teo (2007). Afterward, they were consulted with experts and then given to the students for trials. Among 67 samples, the tests have acceptability for the consistent internal reliability between 0.60 and 0.70 (Hair, Black, Babin, \& Anderson, 2010). The Cronbach's alpha of the MCK was 0.619, and the MPCK was 0.641. Pretests were given to the three classes (PBL1, PBL2, and Conventional Teaching) proving that both experimental and control classes were similar in terms of competence. The analysis of this study used the normalized gain value $<$ g> of MCK and MPCK data adopted from Hake (1998) for progress measurement.

$$
<\mathrm{g}>=\frac{\text { (postest-pretest) }}{(100 \text {-pretest) }}
$$

The subject of mathematics is compulsorily given by all pre-service teachers in the second year of the program to the three observed classes belonging to this batch of year weekly for 2 hours. The overall teaching duration of this research is 12 hours for each class, while one lecturer in these three classes teaches Arithmetic and Geometry with the topics of number, fraction, circumference, area, and volume.

The BCKL test contains basic knowledge of numbers, arithmetic operations, circumference, and area. The test questions were prepared by referring to the materials of the elementary teacher education program. Afterward, the questions were consulted through discussions with experts, which were one mathematic education expert, four 
mathematics education lecturers, and one mathematics lecturer of a teacher education program. The discussions were carried out to determine the feasibility of the test in measuring the basic knowledge of the pre-service teachers. The sample question of the BCKL test is as follows.

The circumference of a rectangle is $98 \mathrm{~cm}$. The length is three times the width plus $5 \mathrm{~cm}$. Determine the area of the rectangle?

The MCK aspects test in this study was adopted from Ball, Phelps, and Thames

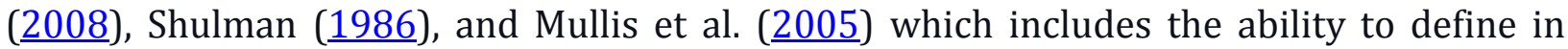
Mathematics or Common Content Knowledge (CCK/knowing), to present mathematics ideas appropriately or Specialized Content Knowledge (SCK/applying), and to connect the interconnected Mathematical ideas or Horizon Content Knowledge(HCK/ reasoning). The sample question of the concepts of circumferential and area is as follows.

Is there any difference in understanding between area and circumference?

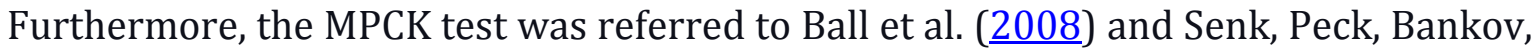
Tatto (2008) containing three aspects: First, the capability of comprehending the mathematics topics (mathematical curricular knowledge) on its structures and interrelatedness; Second, the ability to establish some mathematical representations, methods, procedures for the explanation (utilizing Mathematics for interactive teaching and learning [interactive]), and Third, the ability to anticipate students' misconception ideas (teaching-learning processes utilizing mathematical planning knowledge). The sample question to indicate the students' understanding of the structure and linkages in mathematical topics is as follows.

Are students in the class saying that "Suppose there are two rectangles, if the circumference of the first rectangle is greater than the second rectangle, then the area of the first rectangle will be greater than the second rectangle." What do you think about that?

All three test questions were in the form of essays with scoring techniques referred to Cai, Jakabcsin, and Lane (1996) criteria as shown in Table 1.

Table 1

Scoring criteria

\begin{tabular}{crl}
\hline Score & \multicolumn{1}{c}{ Criteria } \\
\hline \multicolumn{1}{c}{ Students are able to: } \\
a. give a complete answer with clear and unambiguous explanations, \\
b. provide a complete answer with correct definition and algorithm, \\
c. insert a suitable and complete diagram, and \\
d. identify correct mathematical ideas that relate to other mathematical ideas. \\
Students are able to: \\
a. provide an almost complete answer with clear and reasonable explanations, \\
b. provide almost correct information, \\
c. provide an almost complete definition with almost complete algorithms, \\
d. identify an almost complete mathematical idea, but it contains some minor errors. \\
Students are able to: \\
a. show meaningful progress, but there are ambiguous or unclear explanations, \\
b. make calculations with few errors, \\
c. give answers with some vague things or hard-to-interpret things, \\
d. provide incomplete information \& definitions of a concept, and \\
e. identify limited mathematical ideas.
\end{tabular}


Table 1

Continued

\begin{tabular}{|c|c|}
\hline Score & Criteria \\
\hline 1 & $\begin{array}{l}\text { Students are able to: } \\
\text { a. show some correct points in their answers, but the answers are however } \\
\text { incomplete, } \\
\text { b. give answers but with inappropriate information to the situation of the problem, } \\
\text { or unclear diagrams that are difficult to interpret, } \\
\text { c. provide explanations or descriptions with the incorrect path that is difficult to } \\
\text { follow. }\end{array}$ \\
\hline 0 & $\begin{array}{l}\text { Students give ineffective answers, do not show mastery of the material, unable to count, } \\
\text { unable to define a concept, and unable to represent mathematical ideas. }\end{array}$ \\
\hline
\end{tabular}

SPSS is used for descriptive statistic analysis, normality test, and inferential test of the obtained data.

\section{Results and Discussion}

\section{Mathematics Content Knowledge Progress}

This study measures the MCK only related to procedural calculating ability, giving the definition of a concept, representing a mathematical idea, and correlating mathematical ideas. The MCK data of the students were measured through a test consisting of 6 descriptive questions.

The average MCK progresses on low BCKL for conventional learning class, PBL1 class, and PBL2 class consecutively were 0.095; 0.245; and 0.300. The average MCK progresses on medium BCKL in all three classes consecutively were $0.194 ; 0.200 ; 0.368$. Meanwhile, the average MCK progresses on high BCKL in all three classes consecutively were 0.237; 0.248; and 0.279. Based on BCKL aspects of the low, medium, and high categories, the highest average progress occurred in the PBL2 class, followed by the PBL1 class and then the conventional learning class. The highest average MCK progress occurred in the PBL2 class on the medium BCKL group, followed by the low and then the high group. Furthermore, statistical tests are performed to test the differences between the aspects of MCK.

Table 2

Statistical description of MCK

\begin{tabular}{lllccccccc}
\hline \multirow{2}{*}{ Class } & \multirow{2}{*}{ BCKL } & \multirow{2}{*}{ Mean } & \multicolumn{7}{c}{ Statistic } \\
\cline { 4 - 9 } Conventional & Low & 0.095 & 0.095 & 0.111 & 0.002 & 0.045 & 0.045 & 0.130 & 0.085 \\
Learning & Medium & 0.194 & 0.194 & 0.147 & 0.016 & 0.126 & 0.056 & 0.435 & 0.379 \\
& High & 0.237 & 0.237 & 0.237 & 0.005 & 0.069 & 0.188 & 0.286 & 0.098 \\
PBM1 & Low & 0.245 & 0.245 & 0.245 & 0.010 & 0.100 & 0.174 & 0.316 & 0.142 \\
& Medium & 0.200 & 0.200 & 0.205 & 0.012 & 0.107 & 0.063 & 0.400 & 0.337 \\
& High & 0.248 & 0.248 & 0.256 & 0.037 & 0.192 & 0.063 & 0.417 & 0.354 \\
PBM2 & Low & 0.300 & 0.300 & 0.300 & 0.010 & 0.100 & 0.200 & 0.400 & 0.200 \\
& Medium & 0.368 & 0.368 & 0.400 & 0.017 & 0.131 & 0.056 & 0.545 & 0.489 \\
& High & 0.279 & 0.279 & 0.222 & 0.036 & 0.189 & 0.071 & 0.684 & 0.613 \\
\hline
\end{tabular}

For normally distributed data, a different test should be applied by using the test scheme of parametric statistics. In this study, the MCK data were normally distributed. The F-test showed that the Sig value $=0.001<\alpha=0.005$. It means that the average score of MCK progress was different. Therefore F-test can be carried out by looking at F-value $=10.771$, taken from F-table at $\alpha=0.05, F(0.95)(2.66)=3.14$. Since F-value $=10.771$ is greater than $F$ - 
table $=3.14$, it was indicated that there were significant differences among the three studied classes on MCK progress.

Furthermore, Post Hoc Test was given to evaluate which group has better progress than the others. The results of the analysis are presented in Table 3.

Table 3

Post Hoc test of MCK progress viewed from learning approach aspects

\begin{tabular}{ccc}
\hline Class (I) & Class (J) & Asymp. Sig. \\
\hline Conventional & PBL1 & 0.472 \\
Learning & PBL2 & $0.000^{*}$ \\
PBL1 & PBL2 & $0.002^{*}$ \\
\hline
\end{tabular}

The hypotheses for the Post Hoc test are, Ho: there is no significant difference in the progress between the two classes, Ha: there is a significant difference in the progress of the two classes. The Ho is rejected if the score of asymptote significance is lower than $\alpha$, and vice versa. The result showed that the significance value was lower than $\alpha=0.05$ for the groups between the conventional learning class and the PBL2, as well as thePBL1 and the PBL2. Moreover, MCK's progress between pre-service teachers using conventional learning and PBL1 showed no differences.

Furthermore, the Kruskal-Wallis test was carried out to evaluate which class had significant differences in the aspects of knowing, applying, and reasoning. The results of the analysis of test were presented in Table 4.

Table 4

Average difference test of aspects in MCK

\begin{tabular}{|c|c|c|c|c|c|c|}
\hline Aspect of MCK & Class & $\mathrm{N}$ & Mean & Kruskall-Wallis Test & \multicolumn{2}{|c|}{ Mann-Whitney Test } \\
\hline \multirow[t]{3}{*}{ Knowing } & $\begin{array}{l}\text { Conventional } \\
\text { L. }\end{array}$ & 17 & 1.880 & \multirow[t]{3}{*}{$0.002^{*}$} & $\begin{array}{l}\text { Conventional } \\
\text { L.-PBL1 }\end{array}$ & 0.616 \\
\hline & PBL 1 & 22 & 1.320 & & $\begin{array}{c}\text { Conventional } \\
\text { L.-PBL2 }\end{array}$ & $0.009 *$ \\
\hline & PBL 2 & 30 & 3.570 & & PBL1-PBL2 & $0.002 *$ \\
\hline \multirow[t]{3}{*}{ Applying } & $\begin{array}{l}\text { Conventional } \\
\text { L. }\end{array}$ & 17 & 0.000 & \multirow[t]{3}{*}{$0.025^{*}$} & $\begin{array}{l}\text { Conventional } \\
\text { L.-PBL1 }\end{array}$ & $0.013^{*}$ \\
\hline & PBL 1 & 22 & 0.950 & & $\begin{array}{l}\text { Conventional } \\
\text { L.-PBL2 }\end{array}$ & $0.011 *$ \\
\hline & PBL 2 & 30 & 0.600 & & PBL1-PBL2 & 0.666 \\
\hline \multirow[t]{3}{*}{ Reasoning } & $\begin{array}{l}\text { Conventional } \\
\text { L. }\end{array}$ & 17 & 1.760 & \multirow[t]{3}{*}{0.425} & \multirow[t]{3}{*}{ - } & \multirow[t]{3}{*}{-} \\
\hline & PBL 1 & 22 & 1.360 & & & \\
\hline & PBL 2 & 30 & 2.130 & & & \\
\hline
\end{tabular}

The Kruskal-Wallis test between the control and the two experimental classes showed differences in the aspects of MCK progress of the conventional learning, PBL1, and PBL2 classes. The differences occurred in the aspects of knowing and applying with asymptote significance of 0.002 , and 0.025 respectively, which means that there are significant differences for these aspects in all of the three observed classes. Contrarily, there is no significant difference that appeared on the aspect of reasoning with asymptote significance of 0.425 . In other words, the three classes have a similarity in the aspect of reasoning. Table 4 showed that the highest result of the average difference test is on the progress of knowing aspect i.e. the ability to remember the procedure and to give the definition of a mathematical concept. The PBL2 class appeared to have the highest average and median compared to the PBL1 and conventional learning on this aspect. There was 
however no difference in this aspect between the conventional learning class and the PBL1. The aspect of applying, which is the ability to give a representation of mathematics ideas, showed that the significant progress occurred in PBL1 and PBL2 classes. The data in Table 4revealed that the three aspects of the three observed classes have asymptote significance of 0.000 meaning that the three aspects of MCK were significantly different among the three studies classes.

\section{Mathematics Pedagogic Content Knowledge Progress}

This study measured the MPCK only related to some mathematical representations, methods, and procedures for giving explanations, to understand the structure and the relatedness of mathematical topics, and to anticipate the students' misconception ideas. The pre-service teachers' MPCK was descriptively measured using seven testing questions.

Table 5

Statistical description of MPCK

\begin{tabular}{llccccccc}
\hline \multirow{2}{*}{ Kelas } & \multirow{2}{*}{ BCKL } & Mean & Median & Var. & Dev.Std & Min. & Maks. & Range \\
\hline Conventional & Low & 0.1319 & 0.0800 & 0.017 & 0.1302 & 0.036 & 0.280 & 0.244 \\
Learning & Medium & 0.1275 & 0.1252 & 0.004 & 0.0618 & 0.036 & 0.214 & 0.179 \\
& High & 0.1635 & 0.1635 & 0.015 & 0.1224 & 0.077 & 0.250 & 0.173 \\
PBM1 & Low & 0.3093 & 0.3093 & 0.034 & 0.1849 & 0.179 & 0.440 & 0.261 \\
& Medium & 0.2233 & 0.2071 & 0.019 & 0.1382 & 0.038 & 0.524 & 0.485 \\
\multirow{2}{*}{ PBM2 } & High & 0.1975 & 0.2270 & 0.012 & 0.1101 & 0.040 & 0.296 & 0.256 \\
& Low & 0.1987 & 0.2000 & 0.000 & 0.0194 & 0.179 & 0.217 & 0.039 \\
& Medium & 0.1918 & 0.2000 & 0.018 & 0.1355 & 0.036 & 0.591 & 0.555 \\
& High & 0.3505 & 0.3715 & 0.032 & 0.1781 & 0.077 & 0.630 & 0.553 \\
\hline
\end{tabular}

The average MPCK progresses on low BCKL of conventional learning class, PBL1 class, and PBL2 class was consecutively $0.1319 ; 0.3093 ; 0.1987$. The average progresses on medium CBKL in the three classes were consecutively $0.1275 ; 0.2233 ; 0.1918$. The highest average of MPCK progress for low and medium BCKL occurred in the PBL1 class. Besides, the average MPCK progresses on high BCKL in the three classes were consecutively 0.1635; 0.1975; 0.3505. The highest average MPCK progress of high BCKL occurred in the PBL2 class, followed by the low group in PBL1, and medium group in PBL1. Furthermore, statistical tests are performed to test the differences between aspects of MPCK.

Tabel 4

Difference test of MPCK average progress

\begin{tabular}{llrcc}
\hline Aspect & \multicolumn{1}{c}{ Class } & $\mathrm{N}$ & Kruskal-Wallis Test & Asymp.Sig. \\
\hline Teaching & Conventional & 17 & 8.011 & $0.018^{*}$ \\
& Learning & & & \\
PBL1 & 11 & & \\
PBL2 & 30 & & \\
\hline
\end{tabular}

For not normally distributed data, a different test should be applied using the Kruskal-Wallis test. In this study, the MPCK data was not normally distributed. The Kruskal-Wallis test result showed that the significant value $=0.018<\alpha=0.05$. It means that there was a significant difference in MPCK progress among the three studied classes. In other words, there was a difference in MPCK progress among pre-service teachers in conventional learning, PBL1, and PBL2 classes. Since there was a significant difference in MPCK progress, the Post Hoc test is needed to find out which class has the highest progress compared to others. The result of the Post Hoc Test is presented in Table 3. 
Table 5

Post Hoc test of MPCK progress viewed from learning approach aspects

\begin{tabular}{ccc}
\hline Class & Class & Asymp. Sig. \\
\hline Conventional & PBL1 & $0.015^{*}$ \\
Learning & PBL2 & $0.009^{*}$ \\
PBL1 & PBL2 & 0.774 \\
\hline
\end{tabular}

Table 5showed that the MPCK progresses of conventional learning, PBL1, and PBL 2 classes with a significance value of 0.015 and 0.009 are smaller than $\alpha=0.05$. It means that there was a significant difference in MPCK progress between the conventional learning PBL1 and PBL2 classes. The MPCK progress in the PBL1 was higher than in the conventional learning class. The MPCK progress in the PBL2 was also higher than in the conventional learning class. The comparison of the Post Hoc Test between the PBL1 and PBL2 classes gained a significance value of 0.774 , which is bigger than $\alpha=0.05$. It means that there was no significant difference in the MPCK progress of the PBL1 and PBL2 classes.

The following is the Kruskal-Wallis Test on three aspects of MPCK, by comparison, to know which class has a significant difference.

Table 6

Average difference test of aspects in MPCK

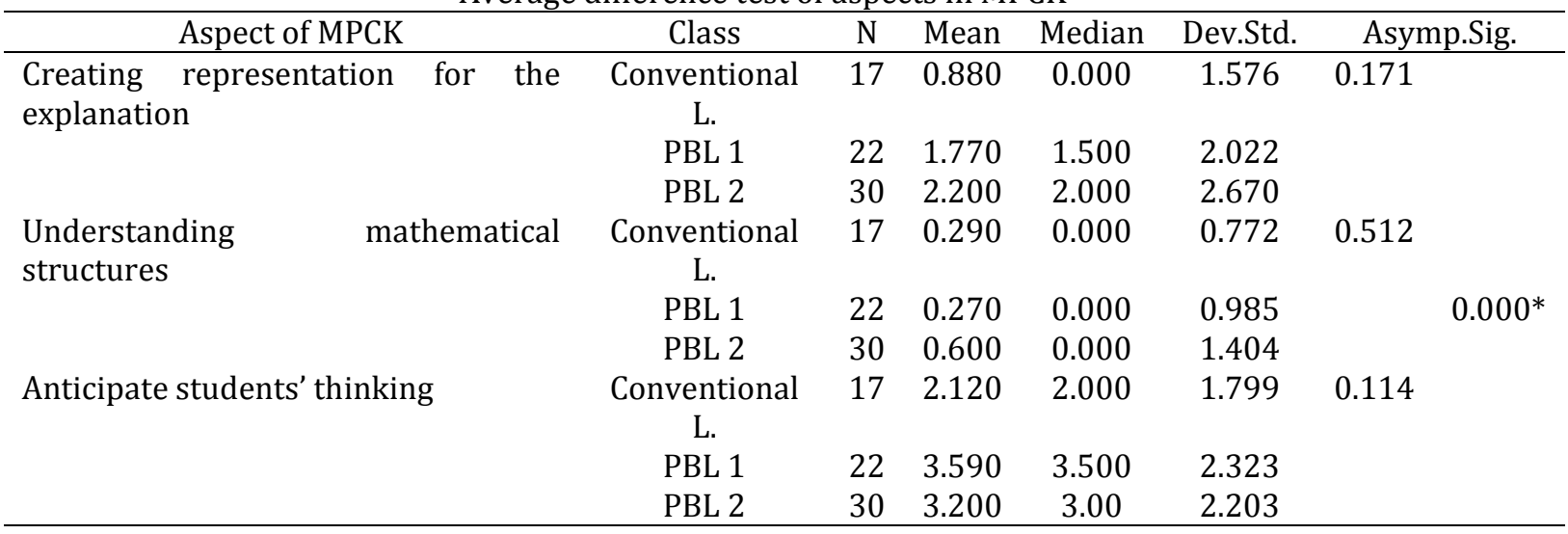

The value of asymptote significance on creating representation for the explanation was 0.171, more than 0.05. It means that the conventional learning class, the PBL1 Class, and the PBL2 class showed no significant difference in the ability to create representation for the explanation. The value of asymptote significance on understanding mathematical structures was 0.512 , bigger than 0.05 . It means that the three studied classes also showed no significant difference in the ability to understand the mathematical structures. Lastly, the value of asymptote significance on anticipating students' thinking was 0.114 , bigger than 0.05. It means that the three studied classes as well showed no significant difference in the ability to anticipate students' thinking.

Table 6 showed that there were differences in the three aspects of MPCK progress with the significance value of 0.000 , less than 0.05 . However, if the comparison is done in each of the MPCK aspects, there was no significant progress difference between the three classes. The mean and standard deviation values of the three observed classes were almost similar. However, despite the similar values, the aspects of MPCK started to appear in PBL1 and PBL2 classes.

The analysis on MCK progress based on the learning approaches and the pre-service teachers' BCKL concludes: First, there was a difference on MCK progress in the conventional learning, PBL1, and PBL2 classes; Second, there was a significant difference of MCK progress between PBL2 class and both conventional learning and PBL1 classes. 
However, there was no significant difference of MCK progress in conventional learning and PBL1 classes; Third, there was no difference on the aspect of reasoning for the three studied classes; Fourth, there was significant progress on the aspect of knowing in PBL2 class; and Fifth, there was significant progress on the aspect of applying in PBL1 and PBL2 classes.

The PBL approach in this study, designed with two models, used almost similar teaching materials. In PBL1, which was a content competence model, the pre-service teachers were expected to be active in discovering mathematical concepts through the problems. The students had to solve problems individually at the beginning and the group afterward. The classes were divided into heterogeneous groups based on the result of the BCKL test. All classroom activities were based on the Student Activity Sheet (SAS).

The PBL2 model was initially selected to anticipate the MPCK progress, which was predicted to have worse results in PBL1. However, the result of MCK progress in PBL2 was better than PBL1. Tables 2 and 4 showed that the PBL2 has a higher mean value compared with conventional learning and PBL1in the aspect of knowing, reasoning, creating representation, and understanding the mathematical structures.

The progress could be caused by weak material mastery owned by the pre-service teachers. The PBL1, which was a competent content model, had indifferent MCK progress with the MCK progress of the conventional learning class. Martin and Mulvihill (2019) stated that the intellectuality of the pre-service teachers could develop if the lecturers can provide them with an environment that gives experience and maturity.

The study on teacher preparation programs using PBL, especially in mathematics classes, was supported by Major and Mulvihill's (2018) research as revealing that PBL could increase pre-service teacher's understanding. According to Major and Mulvihill (ㅁ18), the pre-service teacher's understanding of mathematics is better acquired through the pedagogic comprehension construction of $\mathrm{PBL}$, which is done in an interactive and engaging environment. In PBL2, pre-service teachers are allowed to give mathematicsteaching designs, there are feedbacks from other pre-service teacher fellows on the effectiveness of the practiced teaching design.

A study by Mulyanto, Gunarhadi, and Indriayu (2018) found that PBL could affect the development of students' critical thinking. PBL process provides a broader opportunity for learners to learn content by being involved actively and eagerly. It means that the PBL learners have a positive attitude toward the material. This positive attitude supports them to be successful in learning and strengthen their critical thinking.

In the traditional teaching environment, students learn mathematics through exercises, rules, and equations. However, the materials are limited in an unusual situation. PBL environment (Erickson, 1999; Lubienski, 1999) has a broader opportunity for the students to learn mathematics processes related to communication, representation, modeling, and reasoning.

Based on observation, the learning activities in PBL2 and PBL1 were similar. However, in PBL2, there were 'professional actions' to explain difficult mathematics materials for the students of elementary school teacher education. PBL2 approach performed well because the lecturer allowed the pre-service teachers to explore the mathematical concept in a group, and after that, they were asked to explain the concept in front of the class by turn. In PBL2, each group of pre-service teachers presents materials in front of the class. The other groups responded to demonstrate their understanding of the presentation. These activities encouraged the communication, representation, and mathematics reasoning abilities of the students through the solving of problems found in the materials of elementary school. 
There is a no different result among conventional learning, PBL1, and PBL2 classes regarding the MCK progress in terms of the learning approach and the pre-service teachers' BCKL. The difference of the MCK progress did not occur in the three classes of the high, medium, and low levels. In other words, the MCK progress appeared in all categories. It was indicated that the pre-service teachers' beginning knowledge level does not affect their MCK progress.

The highest average MCK progress in conventional learning, PBL1, and PBL2 classes consecutively appeared on high, low, and medium BCKL categories. The highest MCK progress for the high BCKL category was in conventional learning and PBL1 classes. It appeared since the expected content competence was mastered in the two classes. However, the different results occurred in the PBL2 class. ; In PBL2, the medium CBKL category showed the highest average MCK progress. The problems given in the PBL2 involved students' interest. Thus, it could motivate them to investigate the concept of comprehensively (Duch, 2001).

There were differences in the aspects of MCK progress for the three studied classes. The difference in MCK progress occurred significantly in the aspects of knowing and applying. Otherwise, on the aspect of reasoning, which was the highest aspect of MCK progress, had no significant difference in those three classes under study. On the aspect of knowing, the PBL2 class had a significant difference from the PBL1 class and conventional learning class. In PBL2, pre-service teachers performed higher knowledge progress in remembering procedure and giving the definition of a mathematical concept compared to those of other classes. The pre-service teachers studied the mathematical materials considered uneasy to master that they had the opportunity to learn mathematical content.

The different results of knowing the aspect between PBL1 and PBL2 showed that the class activities did not affect the progress of this aspect in PBL1. According to Sullivan (2011), knowing is mathematics knowledge that enables someone to use it in solving the problem or interpret reality. Therefore there should not be any differences in this aspect. Based on the observation, the implementation of the PBL1 teaching approach was rather difficult. In PBL1, some more competent pre-service teachers dominated the problemsolving activities. Besides, if they did not understand the problem in the discussion, they tended to keep silent and wait until the lecturer asked them.

The analysis of the progress of MCK aspects in the conventional learning class showed that the pre-service teachers with less competence in the aspect of knowing would have difficulty and left behind on other aspects. It is in line with Rowland and Turner's (2007) statement that knowing is the foundation of knowledge development for the following phases of mathematical content mastery. The encouragement from the lecturer to pose questions on the material that they have not understood did not push them to be active. Only some pre-service teachers performed well in this aspect. On the contrary, the learning approaches gave advantages to the PBL1 and PBL2 classes in the aspect of knowing. The lecturer as a facilitator who walked around and checked every group in the class found that some groups had poor beginning knowledge. The lecturer then facilitated the groups to solve the problems based on their beginning knowledge.

For the aspect of applying, the significant progress appeared in PBL1 and PBL2 classes. In both classes, problems in SAS were presented to improve the ability to give a representation of a mathematical idea. In this aspect, the two classes showed no difference. It means that the ability of idea representation was not affected by the professional action model. The content competence model in SAS became a major factor in the progress of this aspect. On the contrary, in the conventional learning class, the lecturer activities provided 
an example and opportunity for pre-service teachers to solve problems was not effective to improve the applying aspect.

The learning activities in PBL1 and PBL2 classes, supplemented with SAS, were to solve problems in groups. The activities helped the participants to share ideas in making mathematics representation. Some pre-service teachers in solving the problems still used calculation as a way to make picture representation. Consequently, some pre-service teachers directly presented the final representation in the form of the picture without being able to explain the idea.

The aspect of reasoning i.e. the ability to make the connections between mathematical ideas in the three observed classes showed no significant difference. This aspect did not perform well in the three classes. The findings of the works done by the pre-service teachers showed that they started to connect ideas between real numbers. The reasoning aspect needs deep knowledge on the material of numbers so that the pre-service teachers could connect their mathematical ideas. This aspect was only found on some pre-service teachers in the three observed classes, especially those with high scores of MCK. The preservice teachers with high mastery of mathematics had advantages in this aspect because they could connect the mathematical ideas with the guide of the facilitator. This finding is in line with Hill, Blunk, et al. (2008) statement that the reasoning needs a lot of mathematical knowledge because the reasoning relates to broader mathematical ideas.

The MPCK progress was also analyzed on the aspect of the learning approach and pre-service teachers' beginning knowledge level. The findings revealed that there was a significant difference in MPCK progress between PBL1 and PBL2 classes with conventional learning classes. On the contrary, there was no significant difference in MPCK progress in PBL1 and PBL2 classes. There was also no significant difference in the aspect of making representation for the explanation of the three observed classes. Besides, there was no significant difference in the aspect of understanding mathematics structures in the three classes. There was also no significant difference in the aspect of anticipating students' thinking in the three classes observed

Based on the study on MPCK progress, the PBL1 and PBL2 approaches did not have any progress difference. However, these approaches were better in developing the MPCK than the conventional learning approach. This happened because the problems given in the learning process were effective in developing the pre-service teachers' knowledge. Accordingly, Duch (2001, p.48) stated that an effective problem always involves the students' interest and encourages them to have a deeper investigation and understanding of the mathematics learning materials given at the elementary level. It was presumed that the PBL2 was able to better enhance the pedagogic knowledge than the PBL1 was. However, this study has proven that there was no difference in the progress of the two learning approaches. The activities in the PBL2 did not improve the pre-service teachers' MPCK. Thus, when comparing two approaches, the PBL2 approach was noticed to tend to develop pre-service teachers' MPCK. The PBL model applied in this experimental study was the content competence model in which the problems were connected to mathematics in schools. This activity had been able to improve the pre-service teachers' mathematical pedagogy knowledge. Martin, Grimbeek, and Jamieson-Proctor (릭) also found that the MPCK progress of PBL classes was higher than that of traditional teaching approach on the subjects of Algebra, Measurement, Geometry, Probability, and Statistics.

The MPCK progress showed no differences in terms of the learning approach and CBKL. The difference did not appear in conventional learning, PBL1, and PBL2 classes for all categories of CBLK. It appeared since, in the learning process in each class, MPCK 
progress occurred in all categories of CBKL. So, it can be concluded that CBKL did not affect the MPCK progress of the pre-service teachers.

The progress of MPCK dealing with the capability of making and presenting representation aspect mathematical structure understanding, and anticipating students' ideas in those three classes under study indicated that there was a difference. However, each aspect did not have any difference in those three classes' understudy. It means that the difference might present when comparing the MPCK aspects found in those three classes under study. The quantitative analysis showed that the treatment did not influence MPCK progress.

On the capability of making and explaining the presentation aspect, those three classes under study showed that they did not have any difference. The pre-service teachers found it difficult to provide examples based on division topics. According to Petrou and Goulding (2011), this aspect is slightly different from the MCK's applying aspect. However, during the learning process, some pre-service teachers were found representing their ideas on living things' fraction division operation. This is dissimilar with the MCK's applying aspect in making and explaining representation since mainly focusing on the capability of providing and explaining representation. Nevertheless, the development of this aspect had begun coming to those three classes under study. Pinilla (2007) identified didactic transposition as a changing "knowledge" into "taught knowledge" requiring more creative pre-service teachers. The pre-service teachers' creativity had not been well developed in those three classes under study of this aspect.

The capability of understanding the mathematical structure aspect $n$ those three classes under study showed that there was no significant difference. The pre-service teachers with high mathematics knowledge or mathematical concept mastery were dominant in those three classes' learning process. The conventional learning class was dominated by the pre-service teachers not well engaging in the learning process. Meanwhile, the PBL1 and PBL2 classes were dominated by pre-service teachers with fast learning ability. However, some pre-service teachers in the PBL1 and PBL2 classes were unable to keep up with the uniquely connected relations of width and circumference at any possible answer that they tended to obtain the fast learners' answers.

The capability of anticipating students' thinking aspects in those three classes did not show a significant difference. This aspect had the highest MPCK test scores in those three classes and tended to keep up with the development of two other MPCK aspects. Fennema and Franke (as cited in Petrou \& Goulding, 2011) explained that the students' way of thinking and learning knowledge is one of most effective mathematics teaching approaches. Some pre-service teachers less frequently showed those three classes under study. In this aspect, some pre-service teachers were able to provide an appropriate

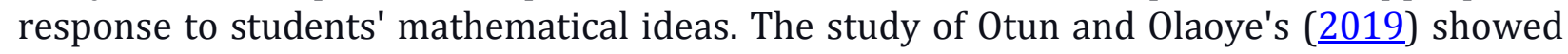
that quasi-experimental research on pre-service teachers using a solve-reflect-pose strategy is better to form conceptual and procedural knowledge than conventional learning. In this study, the pre-service students observed students' mathematical thinking on Algebra and their possible misconception through the strategy applied to the PBL1 class, the result showed that the students in the observed class had a better understanding than those in modified conventional method class.

\section{Conclusion}

The MCK of pre-service teachers in PBL1 and PBL2 classes had good progress as indicated by a significant difference in the aspects of knowing and applying compared to the conventional learning class. The PBL2 class' knowing and applying aspects were better than the PBL1 class'. 
Meanwhile, the MPCK ofPBL1 and PBL2 classes showed good results but did not show any significant difference between both classes. There was also some progress in the conventional learning class but was not as significant as in the other two experimental classes. Based on the results of MCK and MPCK progress, it can be stated that the PBL 2 class' progress is better than the other two classes'. This result is due to the learning process involving authentic problems related to teaching mathematics in elementary schools. The pre-service teachers in the learning process were given a situation where they face mathematical problems, situations related to their profession in the future so that they have a higher responsibility for these problems. However, the learning activity in PBL2, with the addition of professional action activities in the form of teaching other groups, could improve the knowing aspects of PBL2 class more significantly than the PBL1 and conventional learning classes.

This experimental research conducted in one semester has shown positive progress. Further researches are suggested to be carried out more than one semester so that the application of Problem Based Learning (PBL) could have a meaningful influence on the aspects of MCK and MPCK that need to be mastered by pre-service teachers. Finally, this study provides a recommendation that teacher education programs could apply the PBL2 teaching approach as an effort to develop pre-service teachers' MCK and MPCK competencies.

\section{Acknowledgment}

The authors appreciate the pre-service teachers in IAIN Purwokerto who participated in this study.

\section{Bibliography}

Bacon, D. R., \& Stewart, K. A. (2006). How fast do students forget what they learn in consumer behavior? A longitudinal study. Journal of Marketing Education, 28(3), 181192. https://doi.org/10.1177/0273475306291463

Ball, D. L., Hill, H. C., \& Bass, H. (2005). Knowing Mathematics for Teaching: Who knows mathematics well enough to teach third grade, and how can we decide? American Educator, 29(1), 14-17. Retrieved from http://hdl.handle.net/2027.42/65072

Ball, D. L., Thames, M. H., \& Phelps, G. (2008). Content knowledge for teaching: What makes it special? Journal of Teacher Education, 59(5), 389-407. https://doi.org/10.1177/0022487108324554

Cai, J., Jakabcsin, M. S., \& Lane, S. (1996). Assessing Students' Mathematical Communication. School Science and Mathematics, 96(5), 238-246. https://doi.org/10.1111/j.19498594.1996.tb10235.x

Cheang, W. K., Yeo, J. K. K., Chan, E. C. M., \& Lim-Teo, S. K. (2007). Development of Mathematics Pedagogical Content Knowledge in Student Teachers. The Mathematics Educator, 10(2), 27-54. Retrieved from http://hdl.handle.net/10497/102

Cohen, L., Manion, L., \& Morrison, K. (2007). Research Methods in Education. In Routledge. London: Routledge.

Corcoran, T. (1995). Helping teachers teach well: Transforming professional development. In CPRE Policy Briefs /Consortium for Policy Research in Education. New Brunswick: NJ Rutgers.

Darling-hammond, L., \& National Commission on Teaching \& America's Future (U.S.). (1997). Doing What Matters Most: Investing in Quality Teaching. Retrieved from https://files.eric.ed.gov/fulltext/ED415183.pdf

Duch, B. J. (2001). Model for Problem-Based Instruction in Undergraduate Courses. In Barbara J. Duch, S. E. Groh, \& D. E. Allen (Eds.), The Power of Problem-Based Learning. Virginia: Stylus Publishing.

Duch, B. J., Groh, S. E., \& Allen, D. E. (2001). The Power of Problem-Based Learning. Virginia: 
Stylus Publishing.

Erickson, D. (1999). A Problem-Based Approach to Mathematics Instruction. Mathematics Teacher, 92(6), 516-521. Retrieved from https://search.proquest.com/docview/204694122

Grevholm, B., Millman, R., \& Clarke, B. (2009). Function, Form and Focus: The Role of Tasks in Elementary Mathematics Teacher Education. In B. Clarke, B. Grevholm, \& R. Millman (Eds.), Tasks in Primary Mathematics Teacher Education (4th ed.). https://doi.org/10.1007/978-0-387-09669-8 1

Gunawan, I. (2017). Indonesian Curriculum 2013: Instructional Management, Obstacles Faced by Teachers in Implementation and the Way Forward. 3rd International Conference on Education and Training (ICET 2017). https://doi.org/10.2991/icet$\underline{17.2017 .9}$

Hair, J. F., Black, W. C., Babin, B. J., \& Anderson, R. E. (2010). Multivariate Data Analysis: A Global Perspective 7th Edition. Upper Saddle River: Pearson Education.

Hake, R. R. (1998). Interactive-engagement versus traditional methods: A six-thousandstudent survey of mechanics test data for introductory physics courses. American Journal of Physics, 66(1), 64-74.https://doi.org/10.1119/1.18809

Hill, H. C., Ball, D. L., \& Schilling, S. G. (2008). Unpacking pedagogical content knowledge: Conceptualizing and measuring teachers' topic-specific knowledge of students. Journal for Research in Mathematics Education, 39(4), 372-400. Retrieved from https://www.jstor.org/stable/40539304

Hill, H. C., Blunk, M. L., Charalambous, C. Y., Lewis, J. M., Phelps, G. C., Sleep, L., \& Ball, D. L. (2008). Mathematical knowledge for teaching and the mathematical quality of instruction: An exploratory study. Cognition and Instruction, 26(4), 430-511. https://doi.org/10.1080/07370000802177235

Kennedy, M. (1999). The problem of evidence in teacher education. In R. Roth (Ed.), The role of the university in the preparation of teachers (pp. 87-107). Philadelpia: Falmer.

Levin, B. B. (2001). Energizing Teacher Education and Professional Development with Problem-Based Learning. Virginia: Association for Supervision and Curriculum Development.

Lubienski, S. T. (1999). Problem-Centered Mathematics Teaching. Mathematics Teaching in the Middle School, 5(4), 250-255. Retrieved from https://search.proquest.com/docview/231296278

Ma, L. (1999). Knowing and Teaching Elementary Mathematics: Teachers' Understanding of Fundamental Mathematics in China and the United States. Mahwah: Lawrence Erlbaum Associates.

Major, T., \& Mulvihill, T. M. (2018). Problem-based learning pedagogies in teacher education: The case of Botswana. Interdisciplinary Journal of Problem-Based Learning, 12(1). https://doi.org/10.7771/1541-5015.1543

Martin, D. A., Grimbeek, P., \& Jamieson-Proctor, R. (2013). Measuring problem-based learning's impact on pre-service teachers' mathematics pedagogical content knowledge. Proceedings of the 2nd International Higher Education Teaching And Learning Conference (IEAA 2013). Retrieved from http://www.eventm.net/tl2013

Martin, L. E., \& Mulvihill, T. M. (2019). Voices in Education: Teacher Self-Efficacy in Education. Teacher Educator, 54(3), 195-205. https://doi.org/10.1080/08878730.2019.1615030

Mullis, I. V. S., Martin, M. O., Ruddock, G. J., O’Sullivan, C. Y., Arora, A., \& Erberber, E. (2005). TIMSS 2007 Assessment Frameworks. Boston: TIMSS \& PIRLS International Study Center, Lynch School of Education. 
Mulyanto, H., Gunarhadi, G., \& Indriayu, M. (2018). The Effect of Problem Based Learning Model on Student Mathematics Learning Outcomes Viewed from Critical Thinking Skills. International Journal of Educational Research Review, 5(3), 37-45. https://doi.org/10.24331/ijere.408454

Ortiz-Ordoñez, J. C., Stoller, F., \& Remmele, B. (2015). Promoting Self-confidence, Motivation and Sustainable Learning Skills in Basic Education. Procedia - Social and Behavioral Sciences, 171, 982-986. https://doi.org/10.1016/j.sbspro.2015.01.205

Otun, W. I., \& Olaoye, A. A. (2019). Enhancing the Conceptual, Procedural and Flexible Procedural Knowledge of Pre-Service Mathematics Teachers in Algebra. JRAMathEdu (Journal of Research and Advances in Mathematics Education), 4(2), 66-78. https://doi.org/10.23917/jramathedu.v4i2.8363

Petrou, M., \& Goulding, M. (2011). Conceptualising Teachers' Mathematical Knowledge in Teaching. In T. Rowland \& K. Ruthven (Eds.), Mathematical Knowledge in Teaching (pp. 9-25). https://doi.org/10.1007/978-90-481-9766-8 2

Pinilla, M. I. F. (2007). Fractions: conceptual and didactic aspects. Acta Didactica Universitatis Comenianae, (7), 81-115. Retrieved from http://www.ddm.fmph.uniba.sk/ADUC/files/Issue7/05Pinilla.pdf

Rowland, T., \& Turner, F. (2007). Developing and Using the 'Knowledge Quartet': A Framework for the Observation of Mathematics Teaching. The Mathematics Educator, 10(1), 107-123.

Savin-Baden, M. (2003). Facilitating Problem-Based Learning. In The Wiley Handbook of Problem-Based Learning. Philadelpia: The Society for Research into Higher Education \& Open University Press.

Schoenfeld, A. H., \& Kilpatrick, J. (2008). Toward a Theory of Proficiency in Teaching Mathematics. In D. Tirosh \& T. Wood (Eds.), Tools and Processes in Mathematics Teacher Education (Second Edition) (Vol. 2, pp. 321-354). https://doi.org/https://doi.org/10.1163/9789087905460 016

Senk, S. L., Peck, R., Bankov, K., \& Tatto, M. T. (2008). Conceptualizing and measuring mathematical knowledge for teaching: Issues from TEDS-M, an IEA Cross-National Study. Paper Prepared for Topic Study Group 27 (Mathematical Knowledge for Teaching) of the 11th International Congress on Mathematical Education, pp. 1-15. Retrieved from http://tsg.icme11.org/document/get/746

Shulman, L. S. (1986). Those who understand: Knowledge Growth in Teaching. Educational Researcher, 15(2), 4-14. https://doi.org/https://doi.org/10.3102/ 0013189X015002004

Skott, J. (2019). Understanding mathematics teaching and learning "in their full complexity." Journal of Mathematics Teacher Education, 22, 427-431. https://doi.org/10.1007/s10857-019-09446-z

Sorge, S., Kröger, J., Petersen, S., \& Neumann, K. (2019). Structure and development of preservice physics teachers' professional knowledge. International Journal of Science Education, 41(7), 862-889. https://doi.org/10.1080/09500693.2017.1346326

Sullivan, P. (2011). Australian Education Review Teaching Mathematics : Using researchinformed strategies. In Australian Council for Educational Research. Camberwell: Vic: ACER Press.

Tatto, M. T., Schwille, J., Senk, S. L., Ingvarson, L., Peck, R., \& Rowley, G. (2008). Teacher Education and Development Study in Mathematics (TEDS-M) Conceptual framework. East Lansing, MI: Teacher Education and Development International Study Center: College of Education, Michigan State University. 